Research Article

\title{
Pollen and seed flow patterns of Carapa guianensis Aublet. (Meliaceae) in two types of Amazonian forest
}

Karina Martins ${ }^{1}$, Andréa Raposo ${ }^{2}$, Christie A. Klimas ${ }^{3}$, Elizabeth A. Veasey ${ }^{4}$, Karen Kainer ${ }^{3,5}$ and Lúcia Helena O. Wadt ${ }^{2}$

${ }^{1}$ Departamento de Biologia, Universidade Federal de São Carlos, Sorocaba, SP, Brazil.

${ }^{2}$ Embrapa Acre, Rio Branco, AC, Brazil.

${ }^{3}$ School of Forest Resources and Conservation, University of Florida, Gainesville, FL, USA.

${ }^{4}$ Departamento de Genética, Escola Superior de Agricultura 'Luiz de Queiroz', Universidade de São Paulo, Piracicaba, SP, Brazil.

${ }^{5}$ Center for Latin American Studies, Tropical Conservation and Development Program, University of Florida, Gainesville, FL, USA.

\begin{abstract}
Various factors affect spatial genetic structure in plant populations, including adult density and primary and secondary seed dispersal mechanisms. We evaluated pollen and seed dispersal distances and spatial genetic structure of Carapa guianensis Aublet. (Meliaceae) in occasionally inundated and terra firme forest environments that differed in tree densities and secondary seed dispersal agents. We used parentage analysis to obtain contemporary gene flow estimates and assessed the spatial genetic structure of adults and juveniles. Despite the higher density of adults (diameter at breast height $\geq 25 \mathrm{~cm}$ ) and spatial aggregation in occasionally inundated forest, the average pollen dispersal distance was similar in both types of forest (195 $\pm 106 \mathrm{~m}$ in terra firme and $175 \pm 87 \mathrm{~m}$ in occasionally inundated plots). Higher seed flow rates ( $36.7 \%$ of juveniles were from outside the plot) and distances ( $155 \pm 84 \mathrm{~m})$ were found in terra firme compared to the occasionally inundated plot $(25.4 \%$ and $114 \pm 69 \mathrm{~m})$. There was a weak spatial genetic structure in juveniles and in terra firme adults. These results indicate that inundation may not have had a significant role in seed dispersal in the occasionally inundated plot, probably because of the higher levels of seedling mortality.
\end{abstract}

Key words: gene flow, parentage analysis, scatterhoarding, seed dispersal, spatial genetic structure.

Received: January 18, 2012; Accepted: May 21, 2012.

\section{Introduction}

Adult density and spatial distribution of plant populations, in particular the distance between flowering individuals, affect outcrossing rates (Murawski and Hamrick, 1991) and pollen flow distances (Dick et al., 2008). As a consequence, these factors cause spatial genetic structure (SGS) (Hamrick et al., 1993). Although various studies have shown a negative relationship between population density and pollen dispersal (Degen et al., 2004; Hardy et al., 2006; Carneiro et al., 2007; Lacerda et al., 2008), two high-density species (Carapa guianensis and Sextonia rubra) have been found to have pollen flow distances similar to those of low density species (Cloutier et al., 2007a), indicating that density is not always the predominant factor

Send correspondence to Karina Martins. Departamento de Biologia, Universidade Federal de São Carlos, Rod. João Leme dos Santos km 110, 18052-780 Sorocaba, SP, Brazil. E-mail: karimartins@yahoo.com. in determining pollen flow and SGS (Doligez and Joly, 1997). Asynchronous flowering, variation in pollen production among trees and variation in the behavior of animal pollinators can have a significant influence on the mating system (Cloutier et al., 2007a) and pollen flow (Dick et al., 2008). Carapa guianensis, a species occurring at high densities in inundated forests and at lower densities in terra firme forests (Klimas et al., 2007), provides an excellent opportunity to examine the dissimilarity between pollen flow and seed flow in relation to tree densities.

Seed flow also affects SGS. The primary seed dispersal mechanism directly influences seed flow. Species with primarily short-distance seed dispersal mechanisms, such as gravity or animals with limited mobility, are more likely to show restricted seed flow and considerable SGS (Hardy et al., 2006). Secondary seed dispersal mechanisms may also exist and can complicate hypotheses about seed flow patterns. Dispersal distances greater than those expected for primary seed dispersers are regularly attributed 
to secondary dispersal agents (Schnabel et al., 1998; Nakanishi et al., 2008) but without specifically testing this hypothesis.

Pollen flow studies generally use paternity analysis to evaluate the biological factors that determine pollen dispersal distances (Ward et al., 2005; Dick et al., 2008 and references therein). In contrast, in seed flow studies, pollen and seed flow are estimated directly and compared to the observed pattern of SGS (Schnabel et al., 1998; Sato et al., 2006; Nakanishi et al., 2008) without a priori hypotheses of biotic or abiotic factors that may affect seed dispersal distances.

Paternity analysis is one of the most direct and reliable methods for assessing contemporary pollen flow and uses genotype progeny from selected seed trees (Sork et al., 1999). Parentage analysis, a related method, is used to assign parent pairs of seedlings, saplings or dispersed seeds and estimates the actual pollen and seed gene flow (Meagher and Thompson, 1987). Higher exclusionary power is necessary in parentage analysis since the seed tree and pollen donor are both unknown. Distances between the seedling/sapling and its seed tree are used to estimate seed flow and distances between pollen donor and seed trees are used to estimate pollen flow (Bittencourt and Sebbenn, 2007). In dioecious species, assignment is relatively simple since it is possible to differentiate between male and female trees (see Schnabel et al., 1998; Sato et al., 2006; Bittencourt and Sebbenn, 2007); however, this approach is more complicated for monoecious and hermaphroditic species, which include the majority of tropical tree species.

Seed dispersal is more limited than pollen dispersal for the majority of species studied by parentage analysis (Burczyk et al., 2006; Sato et al., 2006; Bittencourt and Sebbenn, 2007; Nakanishi et al., 2008). In species in which seed dispersal is spatially restricted, e.g., by gravity, it is possible to overcome some methodological difficulties of parentage analysis by considering the closest parent as the seed tree. If only one adult is assigned, it is considered the seed tree (Dow and Ashley, 1996; Bacles et al., 2006; Nakanishi et al., 2008; Oddou-Muratorio and Klein, 2008; Sebbenn et al., 2010). However, no similar studies have been published for Amazonian trees. The majority of recent studies on gene flow in Amazonian species have focused on pollen flow using the Two-Gener approach (Degen et al., 2004; Azevedo et al., 2007; Carneiro et al., 2007; Cloutier et al., 2007a,b; Silva et al., 2008), paternity analysis of progeny of known seed trees (Carneiro et al., 2009) or a combination of these two strategies (Lacerda et al., 2008).

Carapa guianensis is an Amazonian insect-pollinated tree that preferentially occurs in occasionally inundated forests (McHargue and Hartshorn, 1983), although it is also found in high densities in drier forests (Klimas et al., 2007). This species exhibits prolonged moderately synchronous flowering (Hall et al., 1994; Maués M.M., 2006, PhD thesis, Universidade de Brasília, Brasília, DF, Brazil; Klimas C.A., 2010, PhD thesis, University of Florida, FL, USA) although the timing and length of this phenological phase varies among regions. In the Brazilian state of Acre, a four-month flowering peak is followed by a second, smaller peak for a subset of trees (Klimas C.A., 2010, PhD thesis, University of Florida, FL, USA). Carapa guianensis is monoecious and pollinated by small butterflies (Riodinidae and Lycaenidae) and bees (Meliponina) (Maués M.M., 2006, PhD thesis, Universidade de Brasília, Brasília, DF, Brazil). The species is a predominant outcrosser $\left(t_{m}>90 \%\right)$ but is able to self-fertilize; biparental inbreeding is uncommon (Hall et al., 1994; Cloutier et al., 2007a). Gravity is the primary seed dispersal mechanism. Mature fruits are dehiscent capsules that break open upon ground impact, releasing 4-16 seeds (McHargue and Hartshorn, 1983). The seeds tend to germinate below the canopy of the seed tree but mortality rates are high. There are also two mechanisms of secondary seed dispersal: buoyant seeds can be dispersed by water or can be carried and buried by scatterhoarding rodents (McHargue and Hartshorn, 1983). Seed removal experiments with $C$. guianensis (Silva A.C.C., 2009, MSc dissertation, Universidade Federal do Acre, Rio Branco, AC, Brazil) and Carapa procera (Jansen et al., 2004) have shown that dispersal via scatterhoarding rodents is spatially restricted. This restricted dispersal is corroborated by the high aggregation of $C$. guianensis individuals, particularly juveniles (Klimas et al., 2007). Nonetheless, because $C$. guianensis seedfall occurs during the rainy season, trees in inundated areas are possibly better-situated for long distance seed dispersal than those in drier terra firme forests. Even so, the weak but significant SGS observed for this species has been attributed to high pollen dispersal distances (Cloutier et al., 2007b).

The aim of this study was to investigate the patterns of pollen flow and seed dispersal of $C$. guianensis in different forest types (terra firme and occasionally inundated) using parentage analysis. We also evaluated the spatial genetic structure of juvenile and adult individuals. Previous studies found higher densities and spatial aggregation of adults in this occasionally inundated versus terra firme forest (Klimas et al., 2007) and asynchronous flowering in both forest types (Klimas C.A., 2010, PhD thesis, University of Florida, FL, USA). Based on the assumptions that asynchronous flowering affects the patterns of pollen flow and that forest type (terra firme or occasionally inundated) affects the patterns of seed dispersal, our hypotheses were that: (1) pollen flow would be independent of the spatial aggregation of adults because of asynchronous flowering, (2) seed dispersal distances would be greater in the occasionally inundated plot, assuming that secondary seed dispersal via water was more prevalent in this environment and (3) evidence of stronger SGS would be found in terra firme as a consequence of restricted seed dispersal. 


\section{Materials and Methods}

\section{Study area and sample collection}

The study was done in an unlogged area of the Forest Reserve of the Brazilian Agricultural Research Corporation (Embrapa Acre) in the State of Acre, Brazil (latitude $10^{\circ} 01^{\prime} 28^{\prime \prime} \mathrm{S}$, longitude $67^{\circ} 42^{\prime} 19^{\prime \prime} \mathrm{W}$ ). Although this area is an ecological reserve used for research it is easily accessed by neighboring communities. The average annual temperature is $24.5^{\circ} \mathrm{C}$ with a dry season from June to August (Klimas et al., 2007), and the dominant vegetation is classified as humid tropical forest. The region has a slightly hilly topography that includes upland habitat (terra firme) and occasionally inundated areas.

Two 16-hectare plots (400 m x $400 \mathrm{~m})$ were established, one in an upland forest (terra firme) and the other in an occasionally inundated forest, the latter $500 \mathrm{~m}$ from the former. All C. guianensis individuals with a diameter at breast height (dbh) $\geq 15 \mathrm{~cm}$ were mapped and marked (see Figure S1, Supplementary Material). Leaf samples were collected from all marked individuals (203 in the terra firme forest and 294 in the occasionally inundated forest). Immediately after collection, leaf samples were dried in containers with silica gel and sent to the laboratory for genetic analysis. Sampled individuals were grouped into two size classes based on their reproductive potential: plants with $15 \mathrm{~cm} \leq \mathrm{dbh}<25 \mathrm{~cm}$ were considered juveniles and those with $\mathrm{dbh} \geq 25 \mathrm{~cm}$ were considered adults. While individuals with a $\mathrm{dbh} \geq 15 \mathrm{~cm}$ are potentially reproductive (Klimas et al., 2007), those with $15 \leq \mathrm{dbh}<25 \mathrm{~cm}$ frequently produce small numbers of seeds or suspend reproduction (Klimas C.A., 2010, PhD thesis, University of Florida, FL, USA). Based on a radiocarbon date of 785 years for a $C$. guianensis individual with a dbh of $17 \mathrm{~cm}$ (Vieira et al., 2005) coupled with our data that relate stem diameter to growth (Klimas et al., 2011), we suspected that many of the smaller stems in the understory were suppressed adults and not juveniles awaiting release. We recorded 89 adults and 114 juveniles in the terra firme plot and 164 adults and 130 juveniles in the occasionally inundated plot. Although the number of juveniles was higher in the occasionally inundated plot, the relative number of juveniles per adult was higher in the terra firme plot (1.3 compared to 0.8 in the occasionally inundated plot).

\section{Microsatellite genotyping}

Genomic DNA was extracted from leaf samples using the $2 \%$ CTAB (cetyltrimethylammonium bromide) procedure (Doyle and Doyle, 1990). We used seven pairs of SSR (Simple Sequence Repeats) primers for C. guianensis; five were developed by Vinson et al. (2005) and two by Dayanandan et al. (1999). The forward primers were marked for fluorescent detection. Polymerase chain reactions (PCR) were done in a final volume of $6 \mu \mathrm{L}$ containing $1 \mathrm{ng}$ of genomic DNA, $1 \mathrm{X}$ of PCR reaction buffer $(10 \mathrm{mM}$ Tris$\left.\mathrm{HCl}, \mathrm{pH} 8.3,50 \mathrm{mM} \mathrm{KCl}, 1.5 \mathrm{mM} \mathrm{MgCl}_{2}, \mathrm{pH} 8.3\right), 0.25 \mu \mathrm{M}$ of each primer, $0.27 \mathrm{ng}$ of BSA $/ \mathrm{mL}$ (New England Biolabs, Ipswich, MA), $0.27 \mathrm{mM}$ dNTP and $0.125 \mathrm{U}$ of Taq polymerase (Phoneutria, Belo Horizonte, Brazil) and autoclaved ultrapure water. DNA amplifications were done using ABI 9600 and ABI 9700 thermal cyclers (Applied Biosystems, Crescent City, CA, USA) under the following conditions: $94{ }^{\circ} \mathrm{C}$ for $5 \mathrm{~min}, 30$ cycles of $94{ }^{\circ} \mathrm{C}$ for $1 \mathrm{~min}$, the locus-specific annealing temperature for $1 \mathrm{~min}, 72^{\circ} \mathrm{C}$ for $1 \mathrm{~min}$ and, after 30 cycles, a final extension of $72{ }^{\circ} \mathrm{C}$ for $7 \mathrm{~min}$.

Capillary electrophoresis was done using a Perkin Elmer ABI 3700 sequencer. The base-pair alleles were detected and their size estimated using the programs GeneScan v.3.7 (Applied Biosystems) and Genotyper ver. 2 (Applied Biosystems), respectively. Alleles with an estimated size between the defined classes were classified into either the nearest upper or lower size class based on the closest class. To avoid overestimating the number of alleles, in addition to the method cited above we graphed allelic histograms using the program Genotyper and overlaid all alleles on the same plate in which they were detected by PCR.

\section{Genetic diversity and parentage analysis}

The average number of alleles per locus $(A)$, allelic richness $\left(R_{S}\right)$ (Petit et al., 1998), gene diversity $\left(H_{e}\right)$ and fixation index $(F)$ were estimated for juveniles and adults of both plots. The statistical significance of $F$ values was tested using 500 permutations of alleles among individuals and the Bonferroni correction. These analysis were done using FSTAT software ver. 2.9.3.2 (Goudet, 1995). Allelic information for the loci is available in Raposo (2007). A small proportion of null alleles ( $9 \%)$ were estimated only for one locus. Combined exclusionary power for parent pair, genetic identity parameters and parentage inferences were determined with CERVUS ver. 3.0 (Kalinowski et al., 2007). We attempted to determine the possible pollen donor and seed tree of juveniles from the two forest plots by simple exclusion based on multilocus genotypes for all adults in each plot. This technique uses mismatching between parents and offspring genotypes to reject particular parent-offspring hypotheses and has been successfully used in other studies (Dow and Ashley, 1996; Kameyama et al., 2001; Sato et al., 2006; Wang et al., 2010). We considered as candidate parents only adult trees sampled in the same plot as the juveniles. We did not test for parentage between plots since the plots were separated by continuous forest with C. guianensis individuals between plots (see Figure S1, Supplementary Material). Whereas not testing for parents between plots may underestimate seed and pollen flow, testing between plots without accounting for individuals in between the two plots would likely overestimate dispersal distances. In parentage assignment, a minimum 
number of five typed loci was considered and the genotyping error was set at zero, following Hoebee et al. (2007); no mismatching between juveniles and candidate parents was allowed.

In view of our assumption of limited seed dispersal distance for this species, when a juvenile had a parent pair within the plot then the closest parent was considered the seed tree. Although our strategy of considering the closest parent as the seed tree may underestimate seed dispersal distances, this assumption, which was introduced by Dow and Ashley (1996), has been used for monoecious and hermaphroditic species in conjunction with prior knowledge of seed and pollen dispersal vectors (Bacles et al., 2006; Nakanishi et al., 2008; Oddou-Muratorio and Klein, 2008; Sebbenn et al., 2010). This strategy provides conservative estimates of seed dispersal distances (Bacles et al., 2006; Nakanishi et al., 2008; Sebbenn et al., 2010). Distances between the two parents of a given juvenile were used to calculate the pollen dispersal curve and the distance between the juvenile and the seed tree was used to obtain a seed dispersal curve. Differences between pollen and seed flow distances, as well as differences in the pollen flow distances and seed flow distances between forest types, were tested with the Mann-Whitney test using SPSS ver. 15.0 (SPSS, Chicago, IL, USA) since the data had a normal distribution but the variances were not homogeneous. The cryptic gene flow, which is the probability that foreign seeds (from outside the plot) have a multilocus genotype that matches local parents (in the plot), was estimated as described by Dow and Ashley (1996) using the equation $1-P_{e x}^{n p}$, where $P_{e x}$ is the combined exclusionary power for the parental pair (in this study) and $n p$ is the number of putative pollen donors in the plot.

Finally, we compared the distribution of pollen flow distances with the distribution of distances between each seed tree and all the potential parents in each plot to determine whether gene flow distances were a function of the average distance between pollen donors and seed trees. We tested for significance with the Kolmogorov-Smirnov test in SPSS ver. 15.0.

\section{Spatial genetic structure analysis}

We characterized the spatial genetic structure (SGS) in each forest type and within size classes (juveniles and adults) using spatial autocorrelation procedures and calculated the mean kinship coefficients $\left(F_{i j}\right)$ from Loiselle et al. (1995) for ten distance classes of constant intervals. For each distance interval, 95\% confidence intervals (CIs) for the null hypothesis of no genetic structure $\left(F_{i j}=0\right)$ were obtained using the permutation of individuals among distance classes (Loiselle et al., 1995; Vekemans and Hardy, 2004).

Average pairwise $F_{i j}$ estimates were plotted against the logarithm of the pairwise spatial distances to test the overall pattern of SGS in adults and juveniles of each forest type. Under isolation by distance in a two dimensional space, kinship is expected to decrease approximately linearly with the logarithm of the spatial distance (Hardy and Vekemans, 1999). The regression slope $\left(b_{F}\right)$ was used to quantify the extent of spatial genetic structure based on the $S p$ statistic described in Vekemans and Hardy (2004). The $S p$ statistic was obtained by the ratio $-b_{F} /\left(1-F_{(1)}\right)$, where $F_{(1)}$ is the average $F_{i j}$ between adjacent individuals, i.e., the first distance interval included trees $<25 \mathrm{~m}$ apart. The significance of $b_{F}$ was tested by 10,000 permutations of individuals among spatial positions. All computations were done using the SPAGeDi 1.2 program (Hardy and Vekemans, 2002).

\section{Results}

The density of adults ( $\mathrm{dbh} \geq 25 \mathrm{~cm}$ ) in occasionally inundated forest was double that observed in terra firme forest (Table 1) whereas the density of juveniles $(15 \mathrm{~cm} \leq$ $\mathrm{dbh}<25 \mathrm{~cm}$ ) was similar in both environments; juveniles accounted for $56 \%$ of individuals in terra firme and $45 \%$ in occasionally inundated forest. The maximum $\mathrm{dbh}$ was $65 \mathrm{~cm}$ and $58.4 \mathrm{~cm}$ in terra firme and occasionally inun-

Table 1 - Genetic diversity and spatial genetic structure estimates for Carapa guianensis based on seven microsatellite loci.

\begin{tabular}{|c|c|c|c|c|}
\hline \multirow[b]{2}{*}{ Plot } & \multicolumn{2}{|c|}{ Juveniles } & \multicolumn{2}{|c|}{ Adults } \\
\hline & Terra firme & Occasionally inundated & Terra firme & Occasionally inundated \\
\hline$A$ & $6.43(0.84)$ & $7.14(1.42)$ & $6.00(0.79)$ & $8.00(1.38)$ \\
\hline$R_{S}$ & $6.20(0.79)$ & $6.74(1.30)$ & $5.99(0.79)$ & $7.03(1.26)$ \\
\hline$H_{e}$ & $0.606(0.062)$ & $0.594(0.088)$ & $0.612(0.061)$ & $0.603(0.081)$ \\
\hline$F$ & $0.053 *(0.046)$ & $0.006^{\mathrm{NS}}(0.119)$ & $0.023^{\mathrm{NS}}(0.055)$ & $0.009^{\mathrm{NS}}(0.112)$ \\
\hline$D$ & 7.13 & 8.13 & 5.56 & 10.25 \\
\hline$b_{F}$ & $-0.0039 \S(0.0026)$ & $-0.0037 \S(0.0027)$ & $-0.0045 \S(0.0016)$ & $-0.0009^{\mathrm{NS}}(0.0012)$ \\
\hline$S p$ statistic & 0.0040 & 0.0038 & 0.0046 & 0.0009 \\
\hline
\end{tabular}

$A$, average number of alleles/locus; $b_{F}$, regression slope; $D$, number of individuals per hectare; $F$, fixation index; $H_{e}$, gene diversity (Nei, 1987) $R_{S}$, allelic richness based on a sample size of 88 individuals. Standard errors over loci are indicated in parentheses. ${ }^{*} \mathrm{p}<0.05,{ }^{\S} 0.10 \geq \mathrm{p}>0.05$ and ${ }^{\mathrm{NS}} \mathrm{p}>0.10$. 
dated plots, respectively, and both forest types showed similar diameter distribution patterns (data not shown).

Juveniles and adults in both forest types had high levels of genetic diversity (Table 1$)$. Allelic richness $\left(R_{S}\right)$ and gene diversity $\left(H_{e}\right)$ were not significantly different between juveniles and adults in the same plot nor between plots ( $p>0.05$ in all comparisons after 500 permutations). For all estimates of genetic diversity, variation among loci was highest for individuals in the occasionally inundated plot. The fixation index $(F)$ was small and significantly different from zero only for juveniles in terra firme (Table 1).

The total exclusionary probability (parent pair) considering seven loci was 0.9979 and 0.9985 in adults from terra firme and occasionally inundated plots, respectively. The total exclusionary probability for identity was 0.99999 and neither plot had candidate parents with identical genotypes. Identity analysis done with CERVUS ver. 3.0 showed that for the total set of genotypes compared only two juveniles from the occasionally inundated plot shared the same multilocus genotype.

A parent pair was assigned for $80(70.2 \%)$ and 108 (81.7\%) juveniles in terra firme and occasionally inundated forests, respectively. In no case was a juvenile was assigned only one parent. Since we genotyped all individuals and found only one identical genotype we concluded that seed flow from outside the plot was higher in terra firme $(29.8 \%)$ than in the occasionally inundated plot $(18.3 \%)$. The high total exclusionary power meant that the probability of cryptic gene flow was nearly $10 \%$, i.e., 0.094 $\left(1-0.9979^{47}\right)$ and $0.099\left(1-0.9985^{70}\right)$ in terra firme and occasionally inundated plots, respectively. The number of juveniles that matched unrelated trees by chance was $7.5(80$ $\mathrm{x} 0.094)$ and $10.7(108 \times 0.099)$ in the terra firme and occasionally inundated plots, respectively. The percentage of juveniles with both parents outside the plots corrected for cryptic gene flow was $36.7 \%$ in terra firme and $25.4 \%$ in the occasionally inundated plot.

Approximately $53 \%$ of adults sampled in terra firme and $43 \%$ of adults in occasionally inundated forest were identified as pollen parents of the genotyped juveniles. Similar proportions were observed for the number of seed parents (56\% and $44 \%$ of adults in terra firme and occasionally inundated forest, respectively). In both plots, less than $20 \%$ of the pollen dispersal events occurred at distances of less than $100 \mathrm{~m}$ and almost $70 \%$ involved distances of 100-300 m (Figure 1). In both plots, the average pollen dispersal distance was similar $(\mathrm{p}=0.286$; Table 2$)$ and closely followed the average distance between each seed parent and all other adults in the plot. In terra firme forest, the average distance between seed trees and all adults in the plot was $159 \mathrm{~m}$ while in occasionally inundated forest this distance was $124 \mathrm{~m}$. The frequencies of calculated pollen flow events in each distance class were similar to the frequency of potential pollen donors in almost all distance classes (Figure 1). There was no significant dif-
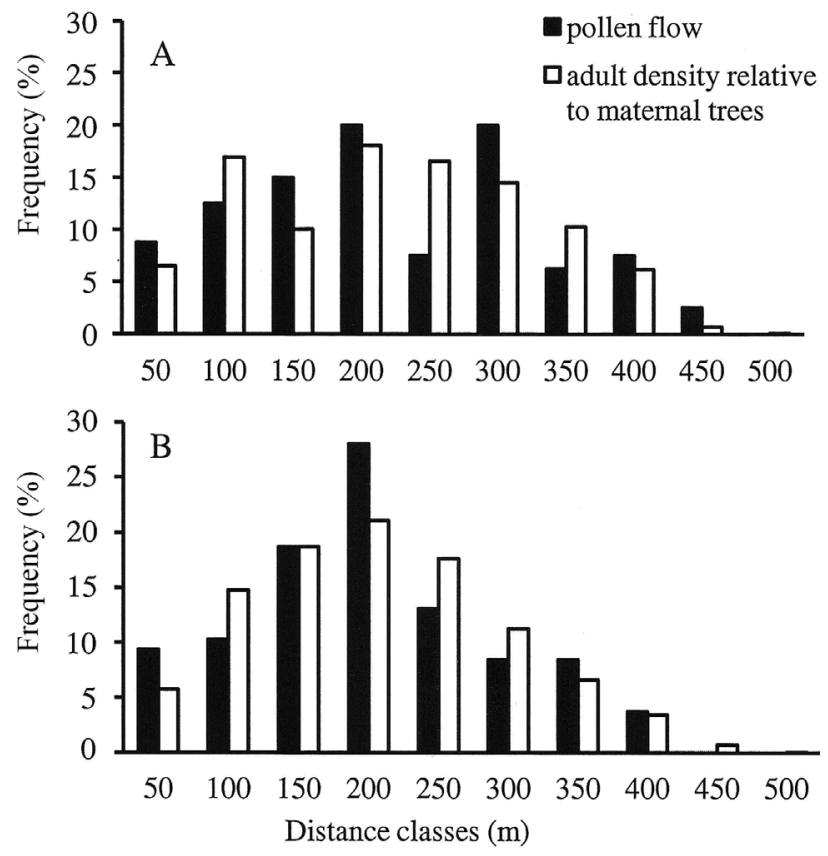

Figure 1 - Frequency histograms of pollen dispersal distances determined by parentage analysis for all juveniles in terra firme (A) and occasionally inundated $(\mathrm{B})$ forests. The average frequency of definite pollen donors was calculated for $50 \mathrm{~m}$ distance classes from the maternal trees (black bars) and plotted together with the frequency of adult trees within each distance class (white bars). Adult trees in each plot were used to calculate the frequency of potential pollen donors in each distance interval.

ference between the pollen flow distribution and the distances between each seed tree and all potential parents in each plot (Kolmogorov-Smirnov $\mathrm{Z}=0.826, \mathrm{p}=0.502$ for the terra firme plot; Kolmogorov-Smirnov $Z=0.691$, $\mathrm{p}=0.726$ for the occasionally inundated forest plot).

The mean seed dispersal distance was significantly higher $(\mathrm{p}=0.001)$ in the terra firme plot than in the occasionally inundated plot (Table 2). Comparison of the frequency distribution of seed dispersal distances (Figure 2)

Table 2 - Pollen and seed dispersal distances estimated for juveniles in terra firme and occasionally inundated plots.

\begin{tabular}{lcc}
\hline Dispersal parameters & Terra firme plot (m) & $\begin{array}{c}\text { Occasionally inundated } \\
\text { plot (m) }\end{array}$ \\
\hline Pollen flow & $195^{\mathrm{a}}$ & $175^{\mathrm{a}}$ \\
Average distance & 181 & 169 \\
Median distance & 106 & 88 \\
Standard deviation & $18-430$ & $23-397$ \\
Distance range & & \\
\hline Seed flow & $156^{\mathrm{a}}$ & $114^{\mathrm{b}}$ \\
Average distance & 149 & 106 \\
Median distance & 84 & 69 \\
Standard deviation & $26-397$ & $4-334$ \\
Distance range & &
\end{tabular}

Different letters indicate that gene flow differed significantly $(\mathrm{p}<0.05$; Mann-Whitey U test). 


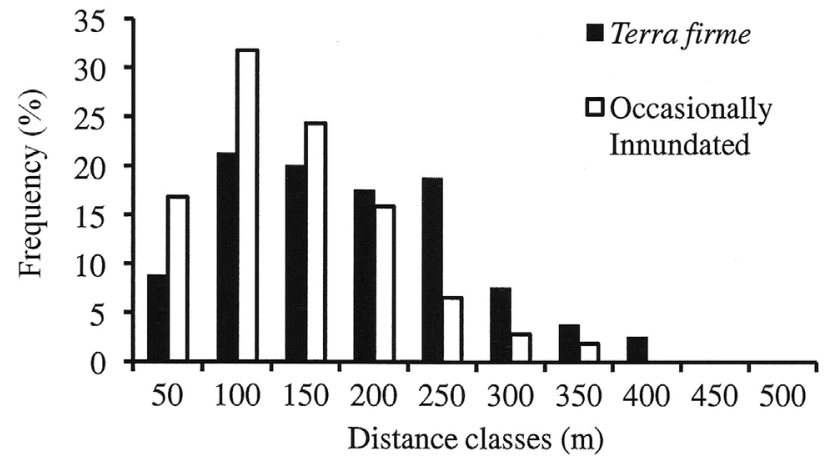

Figure 2 - Frequency histogram of seed dispersal distances determined by parentage analysis for all juveniles in terra firme and occasionally inundated forest plots.

showed that $50 \%$ and $27 \%$ of the seed flow events in the terra firme and occasionally inundated plots, respectively, occurred in the furthest distance classes (>150 m). As expected, the average pollen dispersal distance was significantly higher than the seed dispersal distance in both plots (Mann-Whitney test; $\mathrm{p}=0.02$ in terra firme and $\mathrm{p}=0.000$ in occasionally inundated forest).

The correlograms for juveniles in the two plots and adults in terra firme showed an expected tendency of diminishing kinship with increasing distance between individuals (Figure 3). Although the decrease in kinship began at distances of $25-50 \mathrm{~m}$ the values observed in these distance classes were not significant. Kinship values were high and significant only in the $175 \mathrm{~m}$ distance class for ju-

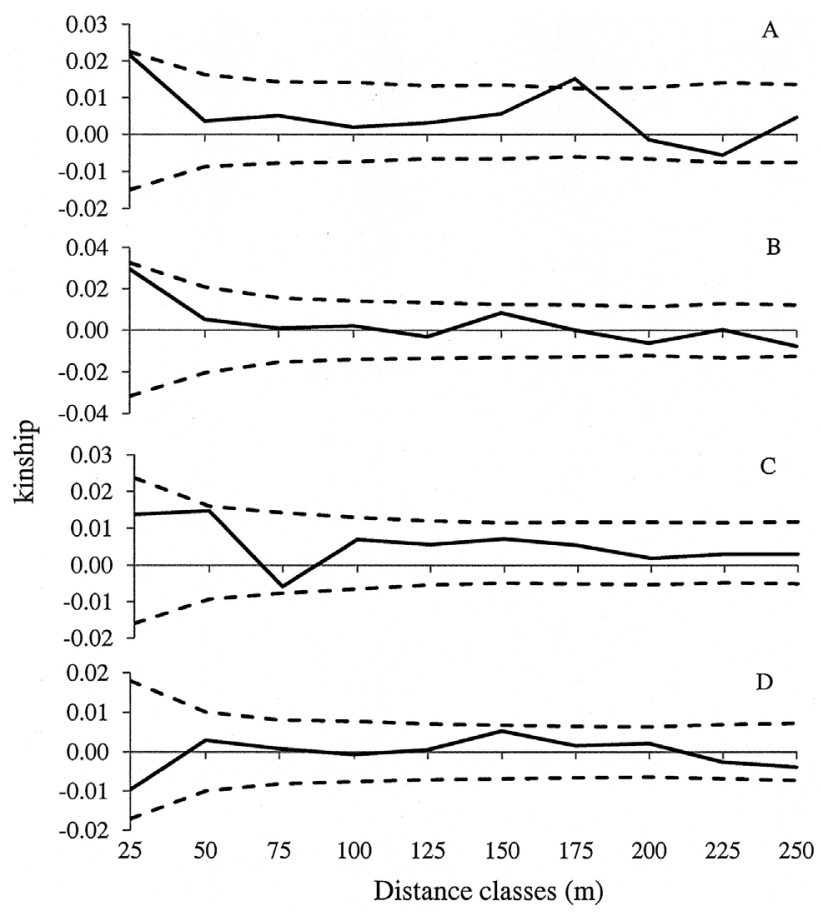

Figure 3 - Correlograms of kinship coefficients $\left(F_{i j}\right)$ over distance intervals for Carapa guianensis juveniles (A) and adults (B) in terra firme forest and juveniles (C) and adults (D) in occasionally inundated forest. veniles in terra firme forest (Figure 3A). Consequently, no SGS was observed for $C$. guianensis, probably because of the small scale of this study. The regression slope $\left(b_{F}\right)$, a measure of SGS, was low and nearly significant for juveniles in both blots $(\mathrm{p}=0.052)$ and in adults in terra firme forest $(\mathrm{p}=0.060)$ (Table 1$)$. Since the estimates of $F_{(1)}$ were almost zero, $S p$ statistics were numerically similar to $b_{F}$. Regression slopes were not different between juveniles and adults or between populations in the two forest types, primarily because of the high standard error for estimates, indicating that local densities did not affect SGS (Table 1).

\section{Discussion}

\section{Pollen dispersal patterns}

Large pollen dispersal distances were observed in both forest types. The average pollen dispersal distances were similar even though the density of reproductive individuals in terra firme was almost half of that observed in occasionally inundated forest (Table 2). Pollen flow distances were slightly larger than estimates obtained by Cloutier et al. (2007b) - 75-265 m depending on the dispersion kernel used - for a population of C. guianensis in the Western Amazon with a lower density of reproductive adults ( 2.5 trees with a dbh $\geq 30$ per ha). These differences may reflect the methods used to infer contemporary pollen flow. Our study used parentage analysis, a direct method that normally gives the most accurate results. In contrast, Two-Gener is an indirect method based on assumptions from distribution models and can result in underestimates of pollen dispersal (Smouse and Sork, 2004). The extensive pollen dispersal distances observed for C. guianensis were more similar to those for species that occur at lower densities $(<1$ tree/ha) than for species that occur at high densities (Cloutier et al., 2007a), although these authors suggest that the influence of density is most important in populations with more than 5 trees/ha.

The density in our study was higher than 5 trees/ha, but flowering phenology and pollinator behavior may have influenced the pollen dispersal distances. A four-year phenological monitoring of reproductive trees at our study site showed that the percentage of individuals that flowered in each reproductive period was highly variable; in addition, there was only moderate flowering synchrony, with the percentage of flowering ranging from $21 \%$ to $91 \%$ in different years (Klimas C.A., 2010, PhD thesis, University of Florida, FL, USA). Although we did not study the spatial dynamics of flowering for all trees in the two plots studied, if individuals close to each other differed in the onset of flowering by even a few days this could be enough to encourage longer-distance pollen dispersal. Pollen carryover may also account for high pollen dispersal distances (Dick et al., 2008). Evidence for this can be seen in our results from parentage analysis. Despite the high population density and aggregation of individuals in both forest types, approxi- 
mately $70 \%$ of pollen flow events occurred at distances of 100-300 m. Since the flowering period lasts for months, the variability within these flowering periods may confer an evolutionary benefit to this species by promoting genetic mixing in these populations. In addition to potential temporal differences in flowering between neighboring trees, not all trees flowered in all years.

\section{Seed dispersal patterns}

The seed dispersal distance in terra firme (156 m) was significantly higher than in occasionally inundated forest $(114 \mathrm{~m})$. We suspect that larger animals were not responsible for seed dispersal since nearby residents stated that hunting has locally eliminated some of the larger fauna, including deer, peccaries and tapirs, from these forests. Carapa guianensis seeds that fall below the seed tree canopy can experience secondary dispersal by scatterhoarding rodents and water, but would also experience higher mortality rates (Rigamonte-Azevedo V., 2010, MSc dissertation, Universidade Federal do Acre, Rio Branco, AC, Brazil). Ecological studies with $C$. procera, a closely related species, have shown short average seed dispersal distances by scatterhoarding rodents (mean $\pm \mathrm{SD}=18.5 \pm 0.9 \mathrm{~m}$; median $\pm \mathrm{SD}=12.5 \pm 0.7 \mathrm{~m}$; Jansen et al., 2004). The same study, however, also documented one seed that was carried $124 \mathrm{~m}$ from the seed tree. Our study differs from that of Jansen et al. (2004) since we estimated seed flow from established saplings while they assessed the location of dispersed seeds. Since most seedlings die within the first year and the establishment of new individuals is preferentially away from the parent tree it is possible that the seed dispersal distance assessed by parentage analysis was higher than that found by Jansen et al. (2004). Nonetheless, considering that (1) candidate parents in our study were restricted to a 16-ha area, (2) the method used to estimate seed dispersal provides conservative estimates and (3) parentage was undetermined in $18.3 \%$ and $29.8 \%$ of juveniles in occasionally inundated and terra firme forest, respectively, we believe that our average dispersal distances are underestimates of the true dispersal distances.

An investigation of $C$. guianensis seed removal done at our study site concluded that because seed removal was rare the fauna was unlikely to be the main cause of secondary seed dispersal; rather, rainfall was considered to be the most important cause of secondary seed dispersal (Silva A.C.C., 2009, MSc dissertation, Universidade Federal do Acre, Rio Branco, AC, Brazil). If this is the case, we could assume that dispersal distances would be greater in occasionally inundated forest, which was an initial hypothesis. However, our results indicate that inundation may not have had a significant role in seed dispersal in this area.

Alternately, significantly higher levels of seedling mortality in occasionally inundated forest, as observed by Rigamonte-Azevedo (Rigamonte-Azevedo V., 2010, MSc dissertation, Universidade Federal do Acre, Rio Branco,
AC, Brazil) in the same area, may counteract the higher supposed dispersal in such forest. Wet soil conditions are conducive to fungal growth that is either a symptom or cause of seedling death. Although water dispersal may indeed be higher, as hypothesized by Silva (Silva A.C.C., 2009, MSc dissertation, Universidade Federal do Acre, Rio Branco, AC, Brazil), this may be counteracted by higher seedling death at flooded dispersal sites, even though these forests were not considered floodplain forests and did not have consistent yearly flooding. While inundation may play a role in determining seed fate, this may be outweighed by the different densities between plots that can in turn affect dispersal by fauna.

A study of C. procera seed removal (Jansen et al., 2004) found a direct relationship between fruit availability and removal by rodents. The percentage of seeds removed and seed dispersal distances were higher during periods of seed scarcity. Jansen et al. (2004) argued that, when seed availability is high, rodents prefer to eat seeds as they encounter them. In contrast, when food is scarce, rodents prefer to carry and bury seeds for later consumption. We observed a higher density of reproductive adults and higher mean seed production per hectare in occasionally inundated forest. The percentage of individuals producing seeds was also higher in occasionally inundated forest based on phenological observations begun in September 2005 (Klimas C.A., 2010, PhD thesis, University of Florida, FL, USA), although this difference decreased in high seed production years. The shorter seed dispersal distance in the occasionally inundated plot may be partly a consequence of both the higher plant density and the experimental design: we measured seed dispersal within a restricted plot area that excluded long-distance seed dispersal. In occasionally inundated forest, seeds may be concentrated in patches after water dispersal, leading to high levels of competition and seedling mortality. Some of these patches may have been caused by dispersal obstacles (felled trees or dense undergrowth) and reduced seed dispersal distance in this forest type. Seed dispersal by humans is also a possible explanation for the observed dispersal distances. Both forests are accessible to hunters, Brazil nut collectors and farmers, despite the reserve status of this forest. While we know of no seed harvesting for oil extraction in this area, there is a small local market for $C$. guianensis seed oil that may encourage small-scale collection efforts.

Another potential explanation for the observed seed dispersal patterns could be differential mortality of parent trees in the two plots. A five-year demographic study monitored over 1,300 C. guianensis individuals $\geq 10 \mathrm{~cm}$ in both forest types, as well as all individuals $\leq 10 \mathrm{~cm}$ within smaller subplots (inventory methods detailed in Klimas et $a l ., 2007)$. The survival of individuals was lower in terra firme forests, although this difference was not significant in all size classes (Klimas C.A., 2010, PhD thesis, University of Florida, FL, USA). Higher mortality in terra firme could 
have artificially inflated seed dispersal estimates since only live individuals were genotyped.

\section{Spatial genetic structure (SGS)}

Although ecological studies have shown that the dispersal distance of $C$. guianensis seeds is limited, which contributes to SGS on small scales, we believe that the high population density, the species mating system and the high average pollen dispersal distances contributed to the absence of SGS in this population. A study of 47 plant species (Vekemans and Hardy, 2004) showed that the SGS of tree species is significantly related to the mating system and population density, with lower SGS in outcrossing species and in populations with high densities. Carapa guianensis predominantly outcrosses (Hall et al., 1994; Cloutier et al., 2007a) with a large effective number of pollen donors ( 9.3 to 11.3, Cloutier et al., 2007a). Weak SGS was observed for a population of $C$. guianensis in the Western Amazon ( $S p=0.0045$ for adults and $S p=0.0047$ for juveniles); SGS was significant, but low, for adults (Cloutier et al., 2007b). An absence of SGS was also observed in a population of the closely related species $C$. procera, in French Guiana (Doligez and Joli, 1997).

Our study shows the plasticity of C. guianensis, an Amazonian tree species with a similar genetic structure in two distinct forest types that have different tree densities. Our results reinforce the importance of evaluating various aspects of reproductive biology, including phenology, seed production and regeneration dynamics in different environments to understand the factors that influence pollen and seed flow and, consequently, SGS. Our results support the hypothesis that flowering patterns are more important in determining pollen flow than distances between conspecific reproductive adults; they also reiterate the need for studies that evaluate the effects of secondary seed dispersal and the behavior of animal dispersers on seed flow.

\section{Acknowledgments}

We thank Empresa Brasileira de Pesquisa Agropecuária (EMBRAPA) for providing field staff and laboratory support during this work. We also thank Alexandre M. Sebbenn for helpful comments on this manuscript and two reviewers and the associate editor for critical and constructive comments. A.R. was supported by a $\mathrm{PhD}$ scholarship from Conselho Nacional de Desenvolvimento Científico e Tecnológico (CNPq). This study was supported by Instituto Internacional de Educação do Brazil (IIEB) and the Kamukaia Project (EMBRAPA).

\section{References}

Azevedo VCR, Kanashiro M, Ciampi AY and Grattapaglia D (2007) Genetic structure and mating system of Manilkara huberi (Ducke) A. Chev., a heavily logged Amazonian timber species. J Hered 98:646-654.
Bacles CFE, Lowe AJ and Ennos RA (2006) Effective seed dispersal across a fragmented landscape. Science 311:628.

Bittencourt JVM and Sebbenn AM (2007) Patterns of pollen and seed dispersal in a small, fragmented population of the wind-pollinated tree Araucaria angustifolia in southern Brazil. Heredity 99:580-591.

Burczyk J, Adams WT, Birkes DS and Chybicki IJ (2006) Using genetic markers to directly estimate gene flow and reproductive success parameters in plants on the basis of naturally regenerated seedlings. Genetics 173:363-372.

Carneiro FS, Sebbenn AM, Kanashiro M and Degen B (2007) Low interannual variation of mating system and gene flow of Symphonia globulifera in the Brazilian Amazon. Biotropica 39:628-636.

Carneiro FS, Degen B, Kanashiro M, Lacerda AEB and Sebbenn AM (2009) High levels of pollen dispersal detected through paternity analysis from a continuous Symphonia globulifera population in the Brazilian Amazon. For Ecol Manage 258:1260-1266.

Cloutier D, Hardy OJ, Caron H, Ciampi AY, Degen B, Kanashiro $\mathrm{M}$ and Schoen DJ (2007a) Low inbreeding and high pollen dispersal distances in populations of two Amazonian forest tree species. Biotropica 39:406-415.

Cloutier D, Kanashiro M, Ciampi AY and Schoen DJ (2007b) Impact of selective logging on inbreeding and gene dispersal in an Amazonian tree population of Carapa guianensis Aubl. Mol Ecol 16:797-809.

Dayanandan S, Dole J, Bawa K and Kesseli R (1999) Population structure delineated with microsatellite markers in fragmented populations of tropical tree, Carapa guianensis (Meliaceae). Mol Ecol 8:1585-1592.

Degen B, Bandou E and Caron H (2004) Limited pollen dispersal and biparental inbreeding in Symphonia globulifera in French Guiana. Heredity 93:585-591.

Dick CW, Hardy OJ, Jones FA and Petit RJ (2008) Spatial scales of pollen and seed-mediated gene flow in tropical rain forest trees. Trop Plant Biol 1:20-33.

Doligez A and Joli HI (1997) Genetic diversity and spatial structure within a natural stand of a tropical forest tree species, Carapa procera (Meliaceae), in French Guiana. Heredity 79:72-82.

Dow BD and Ashley MV (1996) Microsatellite analysis of seed dispersal and parentage of saplings in bur oak, Quercus macrocarpa. Mol Ecol 5:615-627.

Doyle JJ and Doyle JS (1990) Isolation of plant DNA from fresh tissue. Focus 12:13-15.

Goudet J (1995) FSTAT, ver. 2.9.3.2: A computer program to calculate F-statistics. J Hered 86:485-486.

Hall P, Orrell LC and Bawa KS (1994) Genetic diversity and mating system in a tropical tree, Carapa guianensis (Meliaceae). Am J Bot 81:1104-1111.

Hamrick JL, Murawski DA and Nason JD (1993) The influence of seed dispersal mechanisms on the genetic structure of tropical tree populations. Plant Ecol 107/108:281-297.

Hardy OJ and Vekemans X (1999) Isolation by distance in a continuous population: Reconciliation between spatial autocorrelation and population genetic models. Heredity 83:145-154.

Hardy OJ and Vekemans X (2002) SPAGeDi: A versatile computer program to analyse spatial genetic structure at the individual or population levels. Mol Ecol Notes 2:618-620. 
Hardy OJ, Maggia L, Bandou E, Breyne P, Caron H, Chevallier M-H, Doligez A, Dutech X, Kremer A, Latouche-Hallé C, et al. (2006) Fine-scale genetic structure and gene dispersal inferences in 10 Neotropical tree species. Mol Ecol 15:559571.

Hoebee SE, Arnold U, Düggelin C, Brodbeck S, Rotach P and Holderegger R (2007) Mating patterns and contemporary gene flow by pollen in a large continuous and a small isolated population of the scattered forest tree Sorbus torminalis. Heredity 99:47-55.

Jansen PA, Bongers F and Hemerik L (2004) Seed mass and mast seeding enhance dispersal by a neotropical scatter-hoarding rodent. Ecol Monogr 74:569-589.

Kalinowski ST, Taper ML and Marshall TC (2007) Revising how the computer program CERVUS accommodates genotyping error increases success in paternity assignment. Mol Ecol 16:1099-1106.

Kameyama Y, Isagi Y and Nakagoshi N (2001) Patterns and levels of gene flow in Rhododendron metternichii var. hondoense revealed by microsatellite analysis. Mol Ecol 10:204-216.

Klimas CA, Kainer KA and Wadt LHO (2007) Population structure of Carapa guianensis in two forest types in the southwestern Brazilian Amazon. For Ecol Manage 250:256-265.

Klimas CA, Kainer KA and Wadt LHO (2011) The economic value of sustainable seed and timber harvests of multiuse species: An example using Carapa guianensis. For Ecol Manage 268:81-91.

Lacerda AEB, Kanashiro M and Sebbenn AM (2008) Long-pollen movement and deviation of random mating in a low-density continuous population of a tropical tree Hymenaea courbaril in the Brazilian Amazon. Biotropica 40:462-470.

Loiselle BA, Sork VL, Nason J and Graham C (1995) Spatial genetic structure of a tropical understory shrub, Psychotria officinalis (Rubiaceae). Am J Bot 82:1420-1425.

McHargue LA and Hartshorn GS (1983) Seed and seedling ecology of Carapa guianensis. Turrialba 33:399-404.

Meagher TR and Thompson E (1987) Analysis of parentage for naturally establishes seedlings of Chamaelirium luteum (Liliaceae). Ecology 68:803-812.

Murawski DA and Hamrick JL (1991) The effect of the density of flowering individuals on the mating systems of 9 tropical tree species. Heredity 67:167-174.

Nakanishi A, Tomaru N, Yoshimaru H, Manabe T and Yamamoto S (2008) Effects of seed and pollen mediated gene dispersal on genetic structure among Quercus salicina saplings. Heredity 102:182-189.

Nei M (1987) Molecular Evolutionary Genetics. Columbia University Press, New York, 512 pp.

Oddou-Muratorio S and Klein EK (2008) Comparing direct $v s$. indirect estimates of gene flow within a population of a scattered tree species. Mol Ecol 17:2743-2754.

Petit RJ, El Mousadik A and Pons O (1998) Identifying populations for conservation on the basis of genetic markers. Conserv Biol 12:844-855.

Sato T, Isagi Y, Sakio H, Osumi K and Goto S (2006) Effect of gene flow on spatial genetic structure in the riparian canopy tree Cercidiphyllum japonicum revealed by microsatellite analysis. Heredity 96:79-84.
Schnabel A, Nason JD and Hamrick JL (1998) Understanding the population genetic structure of Gleditsia triacanthos L.: Seed dispersal and variation in female reproductive success. Mol Ecol 7:819-832.

Sebbenn AM, Carvalho ACM, Freitas MLM, Moraes SMB, Gaino APSC, da Silva JM, Jolivet C and Moraes MLT (2010) Low levels of realized seed and pollen gene flow and strong spatial genetic structure in a small, isolated and fragmented population of the tropical tree Copaifera langsdorffii Desf. Heredity 106:134-145.

Silva MB, Kanashiro M, Ciampi AY, Thompson I and Sebbenn AM (2008) Genetic effects of selective logging and pollen flow in a low-density population of the dioecious tropical tree Bagassa guianensis in the Brazilian Amazon. For Ecol Manage 255:1548-1558.

Smouse PE and Sork VL (2004) Measuring pollen flow in forest trees: A comparison of alternative approaches. For Ecol Manage 197:21-38.

Sork VL, Nason J, Campbell DR and Fernández-Manjarrés JF (1999) Landscape approaches to historical and contemporary gene flow in plants. Trends Ecol Evol 142:219-224.

Vekemans X and Hardy OJ (2004) New insights from fine-scale spatial genetic structure analyses in plant populations. Mol Ecol 13:921-935.

Vieira S, Trumbore S and Camargo PB (2005) Slow growth rates of Amazonian trees: Consequences for carbon cycling. Proc Natl Acad Sci USA 102:18502-18507.

Vinson CC, Azevedo VCR, Sampaio I and Ciampi AY (2005) Development of microsattelite markers for Carapa guianensis (Aublet), a tree species from the Amazon forest. Mol Ecol Notes 5:33-34.

Wang H, Sork VL, Wu J and Ge J (2010) Effect of patch size and isolation on mating patterns and seed production in an urban population of Chinese pine (Pinus tabulaeformis Carr.). For Ecol Manage 260:965-974.

Ward M, Dick CW, Gribel R and Lowe AJ (2005) To self, or not to self A review of outcrossing and pollen-mediated gene flow in neotropical trees. Heredity 95:246-254.

\section{Internet Resources}

Raposo A (2007) Estrutura genética e fluxo gênico de populações naturais de andiroba (Carapa guianensis Aubl., Meliaceae) visando o manejo e a conservação da espécie. $\mathrm{PhD}$ Thesis, Universidade de São Paulo, Piracicaba, Brazil. http://www.teses.usp.br/teses/disponiveis/11/11137/tde-07 082007-114235/publico/AndreaRaposo.pdf (accessed 5 june 2012).

\section{Supplementary Material}

The following online material is available for this article:

Figure S1 - Location of Carapa guianensis trees in the two 16-ha study plots in Rio Branco, Acre, Brazil.

This material is available as part of the online article from http://www.scielo.br/gmb.

Associate Editor: Adriana Hemerly

License information: This is an open-access article distributed under the terms of the Creative Commons Attribution License, which permits unrestricted use, distribution, and reproduction in any medium, provided the original work is properly cited. 


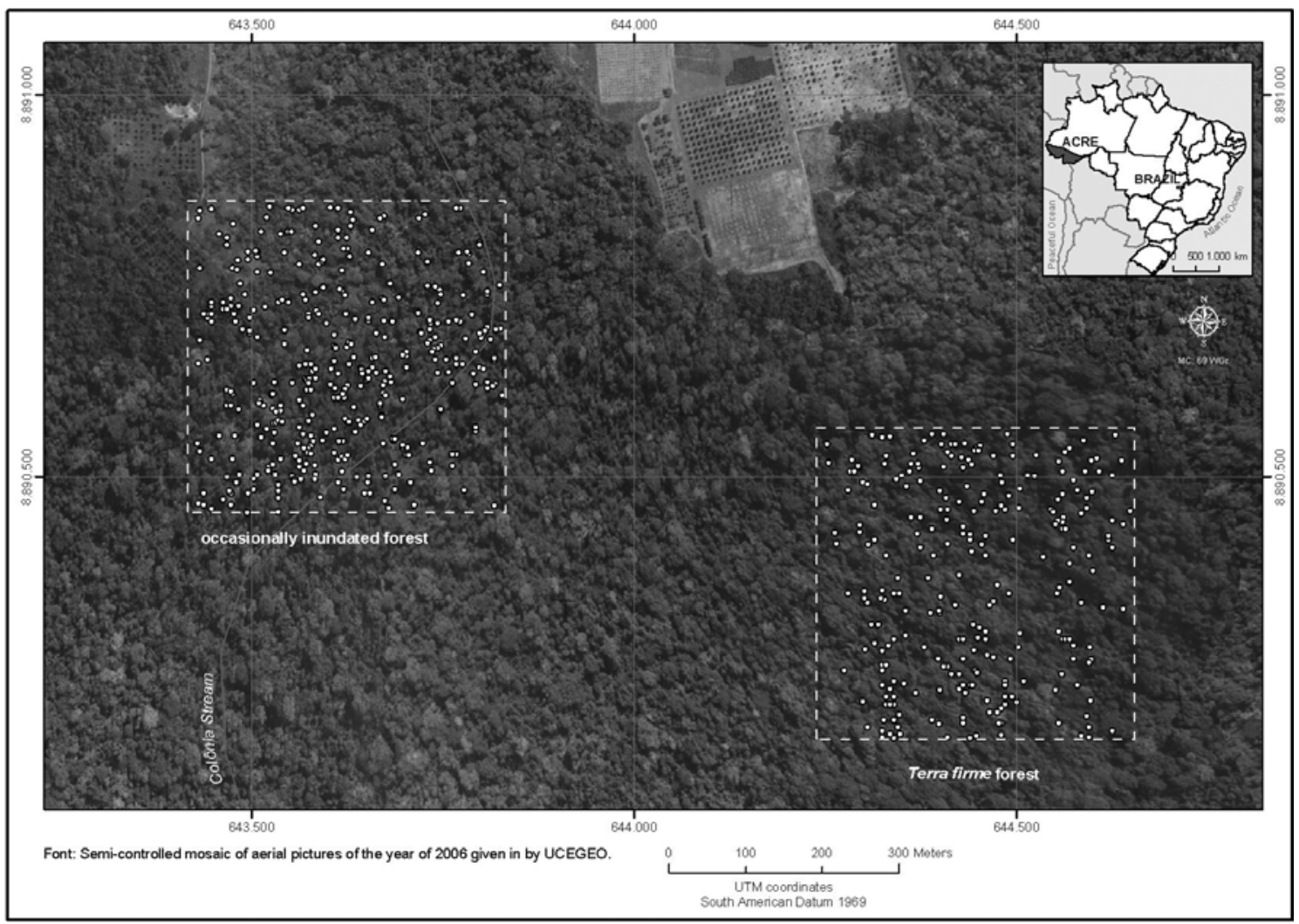

